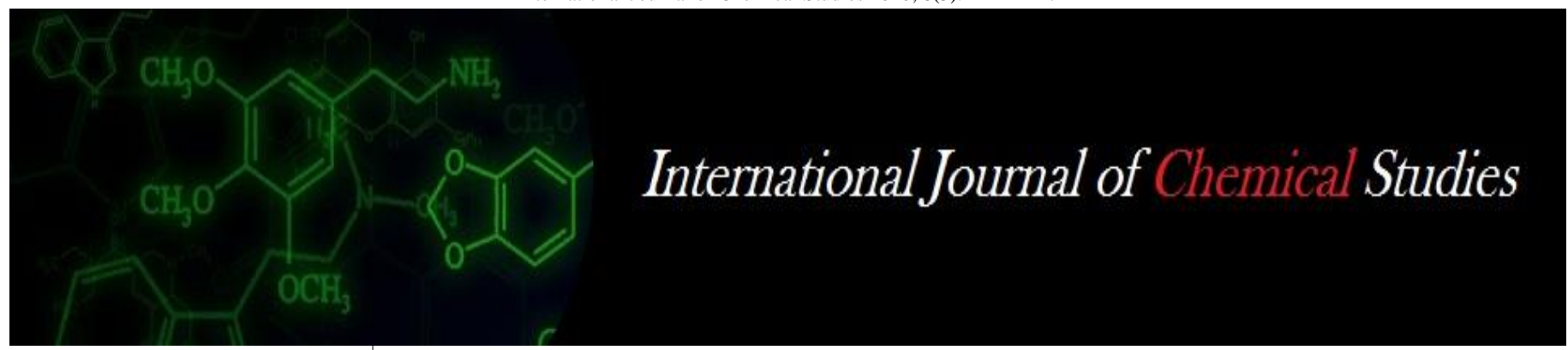

P-ISSN: 2349-8528

E-ISSN: 2321-4902

www.chemijournal.com

IJCS 2020; 8(3): 2411-2417

(C) 2020 IJCS

Received: 07-03-2020

Accepted: 09-04-2020

\section{Shubham Sahu}

College of Fisheries, Central

Agricultural University

(Imphal), Lembucherra, Tripura,

India

Soibam Ngasotter

College of Fisheries, Central

Agricultural University

(Imphal), Lembucherra, Tripura,

India

\section{Manu Mog}

College of Fisheries, Central

Agricultural University

(Imphal), Lembucherra, Tripura, India

\section{Somlang Tesia}

College of Fisheries, Central

Agricultural University

(Imphal), Lembucherra, Tripura,

India

\section{Sanjeev Sharma}

College of Fisheries, Central

Agricultural University

(Imphal), Lembucherra, Tripura,

India

Bandela Dayakar

ICAR-Central Institute of

Fisheries Education (CIFE),

Mumbai, India

\section{David Waikhom}

College of Fisheries, Central

Agricultural University

(Imphal), Lembucherra, Tripura, India

\section{A review on physiological, behavioral and metabolic role of dietary tryptophan in fish}

\author{
Shubham Sahu, Soibam Ngasotter, Manu Mog, Somlang Tesia, Sanjeev \\ Sharma, Bandela Dayakar and David Waikhom
}

DOI: https://doi.org/10.22271/chemi.2020.v8.i3ai.9571

\begin{abstract}
Tryptophan is the sole amino acid in proteins deriving from the indole group that gives an advantage in life chemistry either from metabolizing its $\mathrm{C} 11$ skeleton or using its $-\mathrm{R}$ residue in proteins and peptides for structural stability. The input of tryptophan in a fish from external sources makes it one of the fundamentally essential amino acid supplies that can be managed and controlled in aquaculture practices for desirable performance of physiological and metabolic activities. As the precursor of serotonin, their roles as stress suppressor in several fish species have been well studied. Studies have shown that the enhancement of serotonin synthesis in the brain via supplementary dietary tryptophan has been linked to various behavioral patterns like aggression, stress reaction, feeding, fish maturation, social dominance and sexual behavior. The impact of tryptophan in various physiological, behavioral and metabolic aspects of fish has been generalized in the current review in the hope of futuristic insights and scope in the role that tryptophan plays in fish and aquaculture.
\end{abstract}

Keywords: Tryptophan, serotonin, dietary tryptophan, behavioral pattern, fish maturation, stress suppressor

\section{Introduction}

Among the essential dietary amino acids for fish, tryptophan is one of them which acts as a precursor of serotonin (5-HT) and is known to affect food intake and aggression in vertebrates, including fishes (Wilson 1989) ${ }^{[1]}$. Several behavioral patterns of fish, including aggression (Winberg and Nilsson 1993) ${ }^{[2]}$, feeding (De Pedro et al. 1998; Ortega et al. 2005) ${ }^{[3,4]}$, social dominance (Winberg and Nilsson 1993; Lepage et al. 2005) ${ }^{[2,5]}$, sex behavior (Meston and Frohlich 2000) ${ }^{[6]}$, and reproduction (Prasad et al. 2015) ${ }^{[7]}$ are linked to this indoleamine neurotransmitter. Spinal deformities and cataracts have been observed in those fishes which fed on the TRP-deficient diet. Especially spinal abnormalities such as scoliosis and lordoscoliosis have been reported in salmonids (Akiyama 1984) ${ }^{[8]}$. Through the oral administration of 5-hydroxy-L- tryptophan (5-HTP), a direct precursor of serotonin (Akiyama et al. 1996) [9] the symptoms can be prevented and also it has been reported that 5-HT synthesis in the brain can enhance by feeding of supplementary dietary TRP (Fernstrom and Wurtman 1971; Denbow et al. 1993) ${ }^{[10,11]}$ and can result in decreased aggression activity in fishes such as grouper, Epinephelus coioides (Hseu et al. 2003) [12]; pikeperch, Sander lucioperca (Król and Zakęś 2015) ${ }^{[13]}$. Increased brain serotonergic activity causes an inhibitory effect on aggressive behavior in many vertebrate species (Winberg and Nilsson 1993) ${ }^{[2]}$. Munro (1986) ${ }^{[14]}$ and Maler and Ellis (1987) ${ }^{[15]}$ in teleosts, found that aggressive behavior in the cichlid fish, Aequidens pulcher, and the knife fish, Apteronotus leptorhynchus can be repressed during intracranial injection with serotonin (5-hydroxytryptamine, 5-HT). Adams et al. (1996) ${ }^{[16]}$ reported that aggression of the male firemouth cichlid, Thorichthys meeki, was stimulated by intraperitoneal injection with p-chlorophenylalanine (PCPA), a 5-HT synthesis inhibitor. Thus, the behavior and phenomena being considered as physiological functions of tryptophan or the metabolite, 5-HT, have been well noted in fish. Even in maturation and sexual behavior, the functions of 5-HT also have been reported in some animals. In rats, the steroid hormones by 5 -HT and catecholamines (Arai et al. 1981) ${ }^{[17]}$ the occurrence of sexual behavior has controlled the involvement of brain 5-HT in the secretion of the luteinizing hormone [ $\mathrm{LH}$; equivalent to gonadotropin (GTH) in fish] in female rats has
Corresponding Author: Sanjeev Sharma

College of Fisheries, Central Agricultural University

(Imphal), Lembucherra, Tripura, India 
been suggested by Villalobos et al. (1984) ${ }^{[18]}$. Moreover, by the activity of 5-HT, Peter et al. (1990) ${ }^{[19]}$ observed that the secretion of GnRH and GTH in the fish brain is accelerated and it is depressed by dopamine. Akiyama et al. (1996) [9] also report the positive effect of dietary tryptophan on the maturation of Ayu, Plecoglossus altivelis. In this review, the current knowledge on the role of tryptophan on fish was summarized to provide general insight on the topic for future reference.

\section{Tryptophan: A pivotal chemical structure for living organisms}

The molecular evolution of life in Earth has selected the chemical structure of $-\mathrm{R}$ groups of the 20 L-Amino acids as the most suitable for building proteins. Tryptophan is the only Amino acid in proteins deriving from indole, a bicyclic ring formed by benzene and a pyrrole group. The advantage of keeping indole in life chemistry derives either from the possibility to exploit its $\mathrm{C} 11$ skeleton in metabolism or to utilize it as $-\mathrm{R}$ residue in proteins and peptides to promote and stabilize its structure. Also, tryptophan is metabolized to produce biologically active indole compounds that have a great impact on life functions. Moreover, the study of the metabolic fates of Tryptophan and the other aromatic AAs (AAAs) phenylalanine (Phe) and tyrosine (Tyr) in living organisms has revealed that these pathways represent a "signature" of the cellular evolutionary stages, starting from prokaryote unicellular organisms, passing through eukaryote ancestor cells, arriving then to distinct vegetal or animal eukaryote cells with specific subcellular compartments and trophic features (Tzin and Galili 2010) ${ }^{[20]}$.

\section{Tryptophan Residues in Proteins and Peptides}

The presence of Trp residues in polypeptides deserves a specific mention. The Trp indole ring in $-\mathrm{R}$ residues gives unique properties to proteins and peptides promoting proteinprotein, protein-peptide, or protein-biomolecule structural hydrophobic interactions. The Trp indole ring can stabilize structures, domains, and interactions through Van der Waals forces while the indole- $\mathrm{N}$ show's propensity as a hydrogen bond donor evidencing the role of this AA also in protein binding and recognition. The presence of Tryptophan $-\mathrm{R}$ groups in precise domains, for instance, in trans membrane domains of membrane-bound proteins, is fundamental for the protein stability/assemblage to the phospholipid bilayer (De Jesus and Allen 2013) ${ }^{[21]}$. Hydrophobic interactions between proteins and peptides or between these and other biologically active molecules have great importance in cell physiology. Some reviews show interesting investigations focusing on these structural aspects of tryptophan residues, these works are relevant in the study of both cellular and synthetic (peptidomimetics) peptides, to evaluate the specific function of secondary and tertiary conformational structures (Santiveri and Jimenez 2010) ${ }^{[22]}$. Residues of tryptophan in the amino acid sequence of small bioactive peptides, as endogenous anti-inflammatory/anti-obesity melanocortin peptides or defense antimicrobial peptides of innate immunity (Mojsoska and Jenssen 2015) ${ }^{[23]}$.

\section{Role of tryptophan in fish}

L-tryptophan has one of the most essential nutritional roles contributed to fish. It is not synthesized in the body and is required to be taken from outside that makes it one of the fundamentally essential amino acid, whose supply is very essential for performing normal body physiological and metabolic activities Besides serving as a building block for proteins, tryptophan is also an important nutrient required for the proper functioning of nervous as well as immune systems. Tryptophan acts as a precursor of serotonin (5-HT), which is an indoleamine neurotransmitter (Leathwood 1987) ${ }^{[24]}$. This amino acid is also fount to perform the function as a stress suppressor in some species (Hoglund et al. 2005) ${ }^{[25]}$. The synthesis of 5-HT in the brain can be enhanced by feeding supplementary dietary TRP which is known as linked to several behavioral patterns, including aggression, stress reaction, feeding, social dominance and sex behavior (De Pedro et al. 1998; Schjolden et al. 2006) ${ }^{[3,26]}$. However, some contradictory results do exist when studies on the role of 5HT on aggression and social dominance on some decapod crustaceans were conducted. When supplied exogenously it was found that 5- HT enhances the fight and increases the duration of the fight in crayfish, Astacus astacus and in winner shore crabs, Carcinus maenas showed higher 5-HT levels in their hemolymph.

\section{Effect of tryptophan on growth and survival of fish}

Ahmed and Khan (2005) ${ }^{[27]}$ observed the dietary tryptophan requirement of fingerlings of Indian major carp, Cirrhinus mrigala using six isonitrogenous and isocaloric amino acid test diets through different levels of L-tryptophan $(0.06,0.16$,

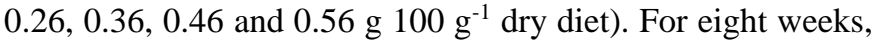
fishes were randomly stocked in triplicate groups in $70 \mathrm{~L}$ flow through indoor circular tanks and fed experimental diets@ $5 \%$ of their body weight. At $0.36 \%$ dietary tryptophan concentration maximum live weight gain, lowest FCR along with the highest protein efficiency ratio were measured. It has been concluded that diets for fingerling of $C$. mrigala should contain tryptophan @0.38 g/100 g dry diet for optimum growth and efficient feed utilization.

Dietary tryptophan requirement of fingerling Rohu, Labeo rohita based on development and body composition was studied by Fatma and Khan (2010) ${ }^{[28]}$. Casein-gelatin based isonitrogenous and isocaloric amino acid test diets simulating the amino acid profile to that of $40 \%$ whole chicken egg protein except for tryptophan were formulated. At $0.40 \%$ tryptophan of the diet maximum LWG (live weight gain), best FCR (1.28), and highest PER (1.95) were recorded. In the range of $0.36-0.38 \%$ by using second-degree polynomial regression analysis the optimum requirement of fingerling $L$. rohita for L-tryptophan is recommended.

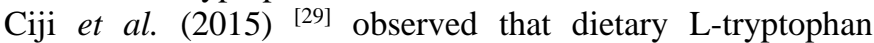
modulates the growth and immuno-metabolic status of $L$. rohita juveniles exposed to nitrite. Fishes that were previously fed normal and elevated levels of tryptophan for 60 days were exposed to nitrite $\left(2.0 \mathrm{mg} \mathrm{L}^{-1}\right)$ for another 45 days with the same feeding regime. There were four treatment groups viz. TRP0-N (control), TRP0+N, TRP0.75+N $\quad(0.75 \%$ supplemented tryptophan in the diet) and TRP $1.5+\mathrm{N}(1.5 \%$ supplemented tryptophan in the diet). Then Highest weight gain $\%$ and specific growth rate (SGR) were observed in control and lowest in TRP0+N after experimenting. Dietary supplementation of elevated levels of tryptophan augmented weight gain \% and SGR. It is concluded, nitrite exposure had adversely affected growth. At the normal requirement of tryptophan, it was unable to struggle the nitrite stress, but dietary fortification with tryptophan (minimum $0.75 \%$ of diet + normal requirement) took place it was found effective in combating nitrite induced stress.

Zehra and Khan (2015) ${ }^{[30]}$ based on growth, protein gain, RNA/DNA ratio, hematological parameters and carcass 
composition studies dietary tryptophan requirement of fingerling Catla catla. In eighteen $70 \mathrm{~L}$ indoor polyvinyl circular troughsa 12 -week feeding trial was conducted. Six casein-gelatin based amino acid test diets $\left(330 \mathrm{~g} \mathrm{~kg}^{-1}\right.$ crude protein; $13.6 \mathrm{~kJ} \mathrm{~g}^{-1}$ digestible energy) which contain graded levels of L-tryptophan $\left(1.0,1.4,1.9,2.3,2.8,3.4 \mathrm{~g} \mathrm{~kg}^{-1}\right.$ dry diet) were fed to triplicate groups of fish near to satiation. Absolute weight gain, feed conversion ratio, protein gain, RNA/DNA ratio, hepatosomatic index, viscerosomatic index, condition factor and hematological indices improved with the increasing levels of tryptophan from 1.0 to $2.3 \mathrm{~g} \mathrm{~kg}^{-1}$ of dry diet. Inclusion of dietary tryptophan in the range of $2.1-2.5 \mathrm{~g}$ $\mathrm{kg}^{-1}$ dry diet, equivalent to $6.4-7.6 \mathrm{~g} \mathrm{~kg}^{-1}$ dietary protein, which is suggested in formulating tryptophan balanced feed for the culture of this fish species.

\section{Importance of tryptophan in fish maturation}

Different environmental factors and hormonal administrations for induced breeding greatly affect the gonadal maturity in fish. For example, the use of photoperiodicity and thermal manipulations has shown positive results in the maturation of ovaries and effective spawning in different cultured fishes. Hormone treatments are now popular methods; e.g. (1) injection of steroid hormones or gonadotropic hormones such as human chorionic gonadotropin (HCG) and homogenate of the fish pituitary gland, (2) implantation of cholesterol pellets and a copolymer of a luteinizing hormone-releasing hormone (LHRH) analogue or native LHRH. Thus, the inclusion of TRP in the diet may be a quite novel method for controlling the maturation process in fish, as this ingredient is legally allowed to use as a feed additive for animals in Japan. To evaluate the effect of oral dosage of tryptophan on the maturation of Ayu (Plecoglossus altivelis), Akiyama et al. (1996) ${ }^{[9]}$ conducted an experiment using Ayu with GSI of $8.0 \%$ in male and $9.0 \%$ of female the experiment was started one month before the usual spawning season, and entirely immature Ayu with GSI below than $0.1 \%$ in both sexes were also used for the study. Three different test diets: i.e., $0.1 \%$ tryptophan, $0.1 \%$ p-chlorophenylalanine (PCPA; depleter of serotonin) diet, or control was feed to them. The peak of serum testosterone level and time of spermiation were superior in males and the final maturation for females was accelerated in the group fed the diet containing TRP, whereas, in ayu that fed on the diet with PCPA, inhibition of serum testosterone levels and the hindrance in the period of spermiation were noted in males, and in females lowering of serum estradiol-17f $\mathrm{A}$ and the delay in the final maturation were observed. So, it is concluded that dietary TRP is involved in the maturation, which is being intermediated by serotonin. Also, these findings indicate the possibility that by oral administration of TRP can improve the maturation of fish.

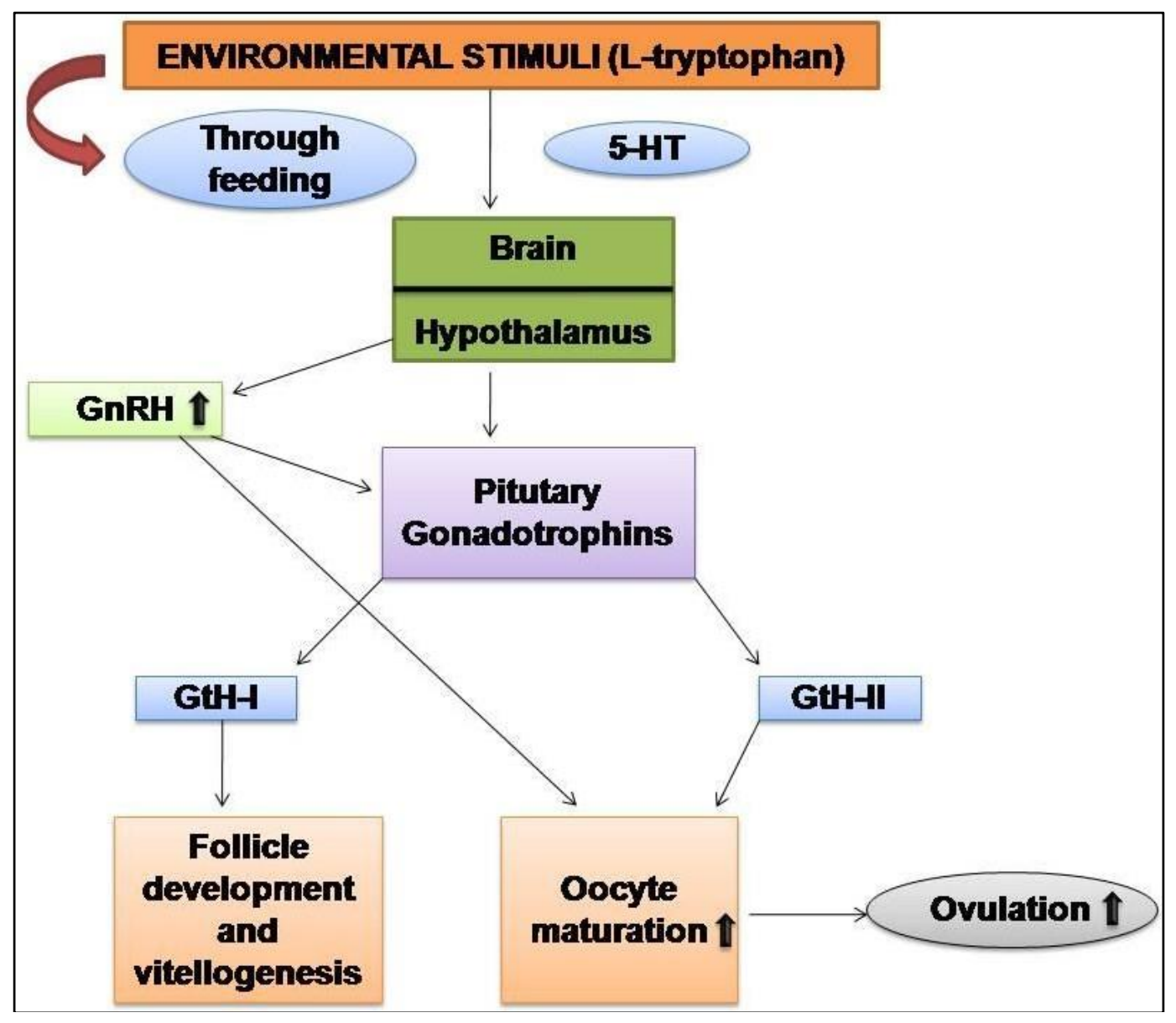

Fig 1: Importance of tryptophan in fish maturation

The occurrence of sexual behavior in rats is controlled through steroid hormones by $5-\mathrm{HT}$ and catecholamines. The involvement of brain 5-HT in the secretion of the LH; equivalent to GTH in female rats was suggested by Villalobos et al. (1984) ${ }^{[18]}$. Moreover, the secretion of GnRH and GTH in the fish brain is accelerated by 5-HT and depressed by dopamine is also reported. In rats brain 5-HT levels are controlled by the dietary TRP levels as TRP is the precursor of 5-HT. Also, in chum salmon fry, the brain 5-HT level can be controlled by dietary TRP level, and the dosage of 5-HTP has been reported by Akiyama et al. (1986) ${ }^{[31]}$. Therefore, the use of TRP may be a quite innovative technique that can 
manipulate fish maturation artificially by feeding an ordinary dietary ingredient.

\section{Tryptophan: As control cannibalism}

Hseu et al. (2003) ${ }^{[12]}$ observed the efficacy of exogenous tryptophan (TRP) on cannibalism, survival and growth in juvenile grouper, Epinephelus coioides. Diets supplemented with TRP @ 0.25\%,0.5\% and 1\% were evaluated in 38-dayold juvenile groupers in 200 L tank @750 fish per tank for 10 days. HPLC analysis showed that TRP-supplemented diets were effective in increasing the levels of 5-HT in the brain of groupers which results in slightly lower cannibalism than in controls. However, body weight and the total length of fishes fed with TRP were significantly smaller than those of control. It has been found that cannibalism among juvenile groupers could be mitigated to the best by the oral administration of TRP @ $0.5 \%$ of the dry diet.

Hoglund et al. (2005) [25] observed that suppression of aggressive behavior in juvenile Atlantic cod (Gadus morhua) by L-tryptophan supplementation. They have found that dietary supplementation with the serotonin precursor, Ltryptophan (TRP) suppresses aggression in juvenile rainbow trout (Onchorhyncus mykiss) and reduces cannibalism in juvenile grouper (E. coioides). A significant decrease in aggressive acts was seen after changing to TRP supplemented feed. The mean number of aggressive acts was also significantly lower in the TRP-treated group compared to a control group not receiving TRP treatment. It has been seen that juvenile Atlantic cod are highly aggressive and supplementing the feed with TRP affects central 5-HT (serotonin) signaling systems and reduces the aggressive behavior.

Kumar et al. (2017) ${ }^{[32]}$ observed the effect of L-tryptophan (TRP) supplemented diets at levels of $0.0,0.5,1.0,1.5$ and $2.0 \%$ on cannibalism, survival and growth performance of Asian seabass, Lates calcarifer fry was evaluated. Thirty days old sea bass fry were reared for 45 days in a recirculating aquaculture system (RAS). Results of the current research showed that TRP supplementation from 0.5 to $2 \%$ in the diet significantly reduced cannibalism compared to the control diet, without affecting the growth performance. The lowest survival percentage $(14 \%)$ was noticed in the control group, whereas a higher survival percentage $(33.33 \%$ to $39.80 \%)$ was observed in TRP supplemented groups. Based on the interpretation of the research, it is recommended to supplement $0.5 \%$ of TRP in the larval diet to reduce cannibalism and improve the survival of sea bass fry.

\section{Tryptophan: As a stress suppressor}

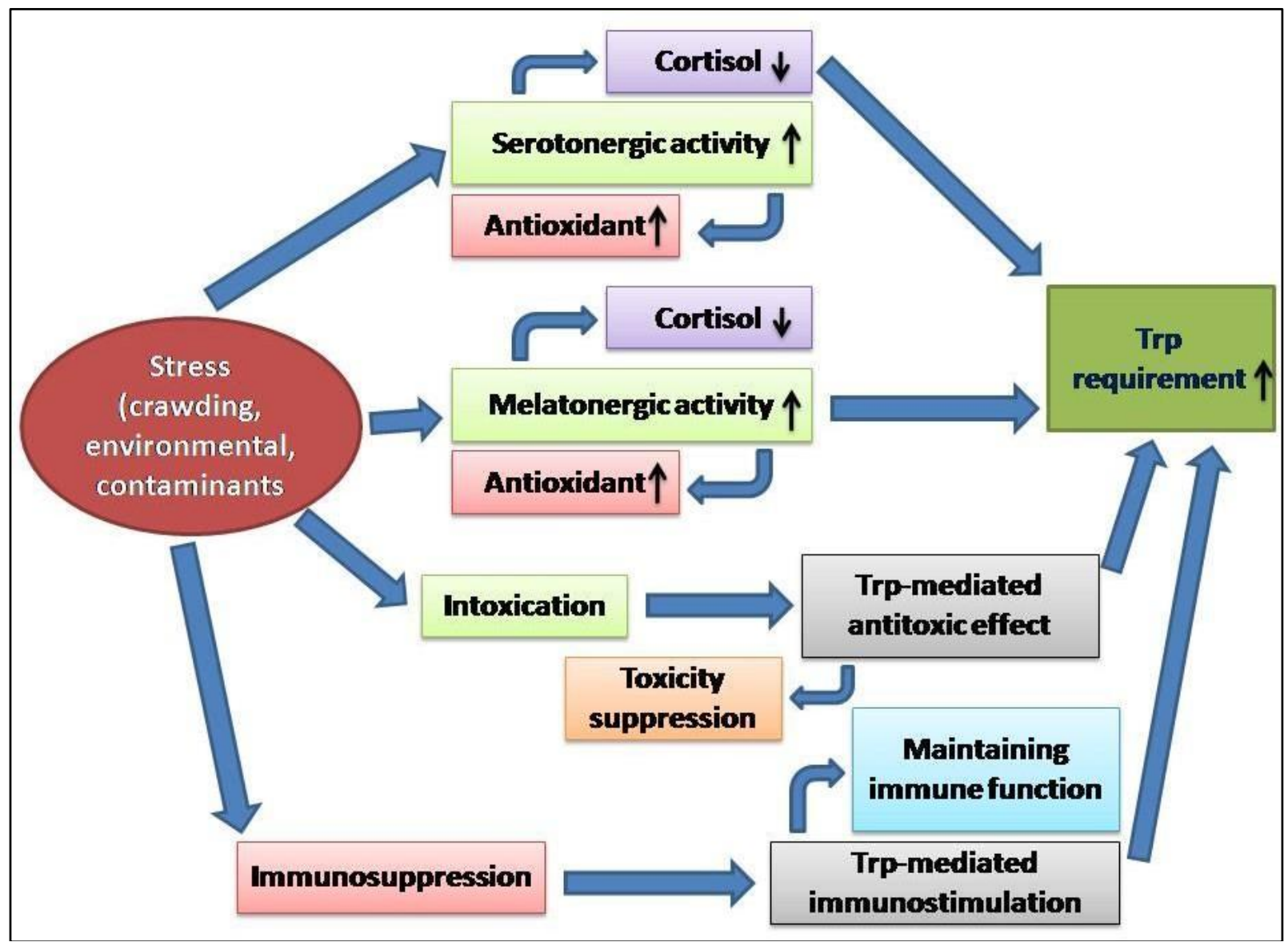

Fig 2: Stressful conditions inducing tryptophan requirement in fish

Chi et at. (2018) ${ }^{[33]}$ studied the immune response and disease resistance of Barramundi, Lates calcarifer (Bloch), offered diets supplemented with replete levels of tryptophan, or whey. A basal diet having $45 \%$ protein, $10 \%$ lipid, and $1.95 \%$ TRP was prepared, and then supplemented with crystalline TRP $(0$, $0.1,0.5$, and $1 \%$ of the diet) or whey $(16.9 \%)$ to evaluate the physiological effects of juvenile barramundi over a 58 days rearing period. Noteworthy reductions in growth and feed intake were observed in fish accessible diets supplemented with Trp as compared to those accessing the basal diet or the whey diet. Phagocytic activity and Mx gene expression in spleens were not appreciably changed among all groups. There were considerable increases in lysozyme activity in the $1 \%$ Trp and whey groups. Increasing mortalities of fish fed 
the whey diet were significantly lower than those fed with basal diet after Aeromonas hydrophila infection, but not Trp groups. Based on these results, diets supplemented with whey had compact mortality when challenged with $A$. hydrophila and therefore function as an immunostimulant.

\section{Tryptophan and melatonin synthesis}

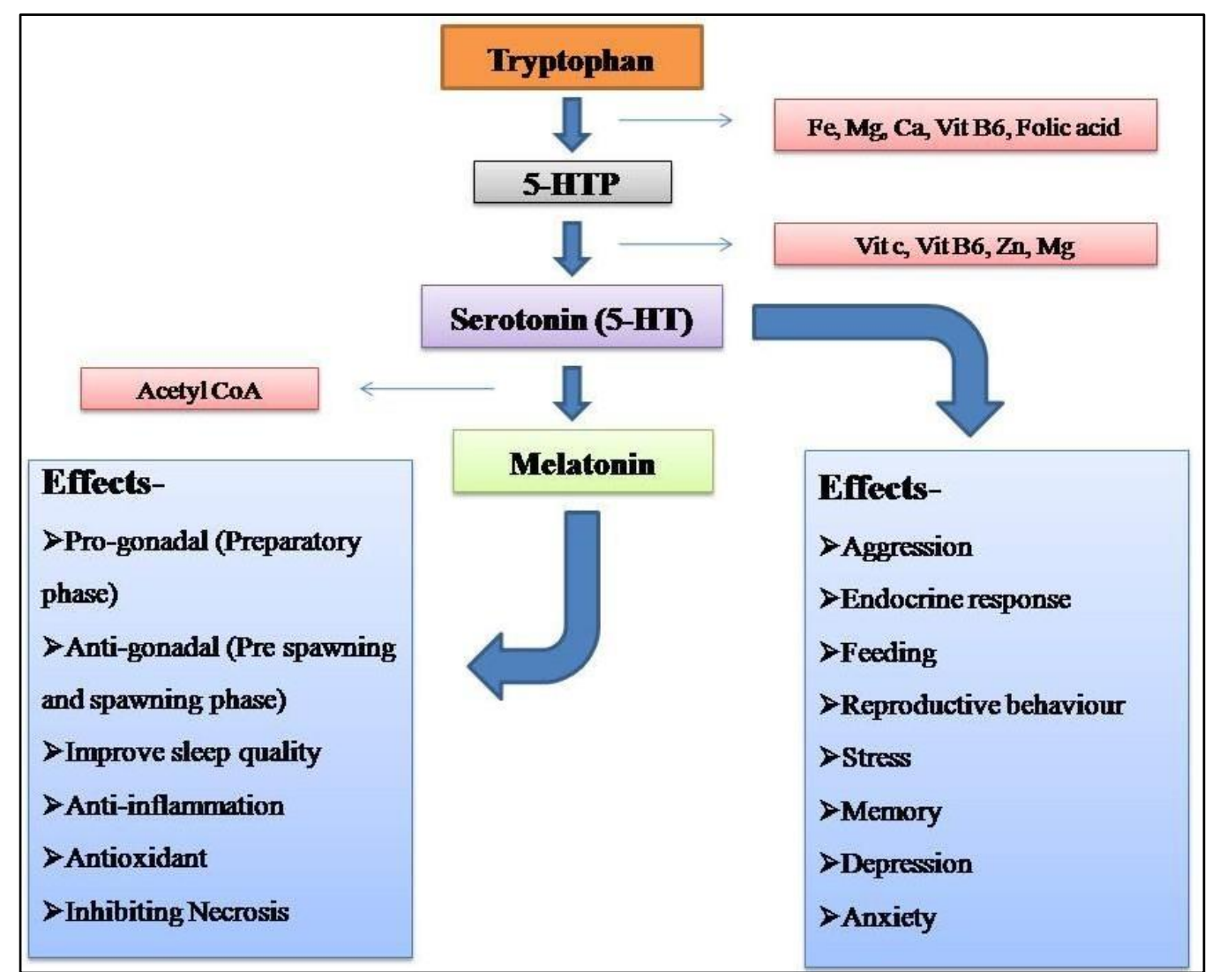

Fig 3: Serotonin and melatonin synthesis and its effect

Melatonin is produced from 5-HT and is a rhythmic hormonal signal involved in the synchronization of daily processes in which the pineal organ and retina play a central role. Therefore, the amino acid tryptophan is also an indirect precursor for the biosynthesis of the hormone melatonin $(\mathrm{N}-$ acetyl-5-methoxytryptamine), which could be partly responsible for the effects observed after tryptophan administration in vertebrates. In melatonin-producing cells, tryptophan is first transformed to 5HT, which is subsequently transformed into melatonin through two enzymatic steps: the transformation of serotonin into $\mathrm{N}$-acetylserotonin, catalyzed by aryl-alkylamine $\mathrm{N}$-acetyl transferase and the subsequent conversion of $\mathrm{N}$-acetylserotonin into melatonin, catalyzed by the hydroxyindole-O-methyltransferase (Falcón et al. 2010) [34]. Melatonin is synthesized through 5HT and is involved in the regulation of several important physiological and behavioral functions, including the mammalian circadian rhythm, patterns of sleep, thermoregulation, reproduction and also immune function (Carrillo-Vico et al. 2005) ${ }^{[35]}$.

The effects of melatonin injections on fish reproduction have been extensively studied, and selected studies only are cited. In one of the first studies, melatonin injections (20 pus/day) were found to have an inhibitory effect on the GSI of both male and female goldfish exposed to a stimulatory LD 16:8 photoperiod (Fenwick 1970) ${ }^{[36]}$. In another study, GSIs were suppressed in both male and female killifish, Fundulus similis, exposed to a stimulatory photoperiod of LD 16:8 by injecting $3 \mathrm{pg}$ melatonin/day in fish weighing $-3 \mathrm{~g}$ (De Vlaming 1974) ${ }^{[37]}$. In control fish, the GSI was lower under LD 8:16 than under 16:8; the GSI was not further suppressed under LD 8:16 by melatonin treatment. Injections of 0.04 $/ \mathrm{g} /$ day melatonin in medaka weighing $-0.4 \mathrm{~g}$ suppressed the GSI in females exposed to a stimulatory LD 16:8 photoperiod (Urasaki 1972) ${ }^{[38]}$, whereas there was no significant effect under short photoperiods or in males kept under long photoperiods. In another study, no effect of pinealectomy was found on already sexually ripe medaka, or of a single melatonin injection (0.02-10 pug) on oocyte maturation and frequency and average timing of ovulation (Iwamatsu 1978) [39]. An inhibitory effect of melatonin injections (20 or 100 pug/day) on ovarian weights, pituitary GTH cells and oocyte maturation was found in the catfish, Heteropneustes fossilis, maintained during the pre-spawning and spawning periods at LD 12:12 (Sundararaj and Keshavanath 1976) ${ }^{[40]}$. On the other hand, no effect of injections of 10 or 100 pug melatonin/day to $H$. fossilis males weighing $-30 \mathrm{~g}$ was found on GSI, seminal vesicle weights, spermatogenesis, or the number of pituitary GTH cells (Keshavanath 1981) ${ }^{[41]}$. The experiment was performed during the pre-spawning period in May-June, and the fish were kept under an LD 12: 12 regime. Further, melatonin administration was found to not affect reproduction in H. fossilis (Garg 1989) ${ }^{[42]}$.

Three-spined sticklebacks weighing $-1 \mathrm{~g}$ were injected with either 0.8 or $4.0 \mathrm{pg}$ melatonin/day for 3 weeks in different seasons and under photoperiods of $8: 16$ or 16:8 (Borg and Ekstrom 1981) ${ }^{[43]}$. The fish showed a higher maturity under LD 16:8 than under 8:16 in late autumn and winter. In these seasons, the high dose of melatonin inhibited oocyte maturation and increased the proportion of females displaying numerous atretic eggs and suppressed kidney hypertrophy [an 
androgen-dependent secondary sexual character in sticklebacks (Borg 1994) ${ }^{[44]}$ in LD 16:8, similar to the effect of LD 8:16]. Significant positive effects of melatonin on female GSI were found under various regimes, but these effects were inconsistent and not correlated with the histological appearance. To summarize, in most studies, melatonin injections have either been without effect on fish maturation or have suppressed reproduction in fishes where long photoperiods stimulate breeding.

Aripin et al. (2015) ${ }^{[45]}$ observed that the effects of exogenous melatonin treatment on the first sexual maturity stage in female broodstock of the Clarias macrocephalus. The gradual melatonin levels of Control ( $0 \mathrm{mg} / \mathrm{kg}$ melatonin), Mt 0.05 (50 $\mathrm{mg} / \mathrm{kg}$ melatonin) and Mt $0.25(250 \mathrm{mg} / \mathrm{kg}$ melatonin $)$ in the diet mixed in isonitrogenous and isocaloric of $37 \%$ crude protein and $9.3 \%$ crude lipid were applied to the first sexual maturation female catfish. After the experiment trial, there was a significant increase in the gonadosomatic index (GSI), fecundity, and egg diameter among female fish in the presence of melatonin after eight weeks of treatment with the mean ranging from $5.61-9.77 \% ; \mathrm{p}=0.001,3034.1-4838.0$ eggs/g; $\mathrm{p}=0.003$, and $1448.4-1555.1 \mu \mathrm{m} ; \mathrm{p}=0.001$, respectively.

\section{Conclusion}

The necessity of exogenous input of tryptophan in fish gives aquaculturists the upper hand in exploiting various aspects of fish physiological and metabolic activity for better production and productivity of aquaculture practices. Though expensive studies on try have been done because of the important roles it plays in fish, not many species have been covered under those studies. Some contradictory results came out from studies on decapods crustacean in their aggression and social dominance (Hubert et al. 1997; Huber and Delago 1998) ${ }^{[46,47]}$. In contrast, aggression and social dominance are also regulated by 5 -HT in some forms of decapod crustaceans. Besides tryptophan requirement in fish has also been observed to vary according to other ecological factors water $\mathrm{pH}$, DO, nitrite content, etc. In addition to fish extracts, dietary supplementation of 5-HT can produce a remarkable property that has been recognized by several researchers around the globe. This calls for further elucidation and research on the subjects for proper optimization of tryptophan dose for individual fish species in aquacultural practices as well as for better growth and survival of fish in general.

\section{References}

1. Wilson RP. Amino acids and proteins. Fish Nutrition. Edn 2, Academic Press, New York, 1989, 111-151.

2. Winberg S, Nilsson GE. Roles of brain monoamine neurotransmitters in agonistic behaviour and stress reactions, with particular reference to fish. Comparative Biochemistry and Physiology Part C: Pharmacology, Toxicology and Endocrinology. 1993; 106(3):597-614.

3. De Pedro N, Pinillos ML, Valenciano AI, Alonso-Bedate M, Delgado MJ. Inhibitory effect of serotonin on feeding behavior in goldfish: involvement of CRF. Peptides. 1998; 19(3):505-511.

4. Ortega VA, Renner KJ, Bernier NJ. Appetite-suppressing effects of ammonia exposure in rainbow trout associated with regional and temporal activation of brain monoaminergic and CRF systems. Journal of Experimental Biology. 2005; 208(10):1855-1866.

5. Lepage O, Larson ET, Mayer I, Winberg S. Serotonin, but not melatonin, plays a role in shaping dominant- subordinate relationships and aggression in rainbow trout. Hormones and behaviour. 2005; 48(2):233-242.

6. Meston CM, Frohlich PF. The neurobiology of sexual function. Archives of General Psychiatry. 2000; 57(11):1012-1030.

7. Prasad P, Ogawa S, Parhar IS. Role of serotonin in fish reproduction. Frontiers in neuroscience. 2015; 9:195.

8. Akiyama T. Scoliosis of fishes caused by tryptophan deficiency. NOAA Technical Report NMFS. 1984, 111115

9. Akiyama T, Shiraishi M, Yamamoto T, Unuma T. Effect of dietary tryptophan on maturation of ayu Plecoglossus altivelis. Fisheries science. 1996; 62(5):776-782.

10. Fernstrom JD, Wurtman RJ. Brain serotonin content: physiological dependence on plasma tryptophan levels. Science. 1971; 173(3992):149-152.

11. Denbow DM, Hobbs FC, Hulet RM, Graham PP, Potter LM. Supplemental dietary L-tryptophan effects on growth, meat quality, and brain catecholamine and indoleamine concentrations in Turkeys. British poultry science. 1993; 34(4):715-724.

12. Hseu JR, Lu FI, Su HM, Wang LS, Tsai CL, Hwang PP. Effect of exogenous tryptophan on cannibalism, survival and growth in juvenile grouper, Epinephelus coioides. Aquaculture. 2003; 218(1-4):251-263.

13. Król J, Zakęś Z. Effect of dietary L-tryptophan on cannibalism, survival and growth in pikeperch Sander lucioperca (L.) post-larvae. Aquaculture International. 2016; 24(2):441-451.

14. Munro AD. Effects of melatonin, serotonin, and naloxone on aggression in isolated cichlid fish (Aequidens pulcher). Journal of pineal research. 1986; 3(3):257-262.

15. Maler L, Ellis WG. Inter-male aggressive signals in weakly electric fish are modulated by monoamines. Behavioural brain research. 1987; 25(1):7581.

16. Adams CF, Liley NR, Gorzalka BB. PCPA increases aggression in male firemouth cichlids. Pharmacology. 1996; 53(5):328-330.

17. Arai Y, Yamanouchi K, Mizukami S, Yanai R, Shibata $\mathrm{K}$, Nagasawa H. Induction of anovulatory sterility by neonatal treatment with $5 \beta$-dihydrotestosterone in female rats. European Journal of Endocrinology. 1981; 96(4):439-443.

18. Villalobos DBD, Lux VA, Mengido ILD, Libertun C. Sexual differences in the serotonergic control of prolactin and luteinizing hormone secretion in the rat. Endocrinology. 1984; 115(1):84-89.

19. Peter RE, Yu KL, Marchant TA, Rosenblum PM. Direct neural regulation of the teleost adenohypophysis. Journal of Experimental Zoology. 1990; 256(S4):84-89.

20. Tzin V, Galili G. The biosynthetic pathways for shikimate and aromatic amino acids in Arabidopsis thaliana. The Arabidopsis book/American Society of Plant Biologists. 2010, 8.

21. De Jesus AJ, Allen TW. The role of tryptophan side chains in membrane protein anchoring and hydrophobic mismatch. Biochimica et Biophysica Acta (BBA)Biomembranes. 2013; 1828(2):864-876.

22. Santiveri CM, Jiménez MA. Tryptophan residues: Scarce in proteins but strong stabilizers of $\beta$-hairpin peptides. Peptide Science. 2010; 94(6):779-790.

23. Mojsoska B, Jenssen H. Peptides and peptidomimetics for antimicrobial drug design. Pharmaceuticals. 2015; 8(3):366-415. 
24. Leathwood PD. Tryptophan availability and serotonin synthesis. Proceedings of the Nutrition Society. 1987; 46(1):143-156.

25. Höglund E, Bakke MJ, Øverli Ø, Winberg S, Nilsson GE. Suppression of aggressive behaviour in juvenile Atlantic cod (Gadus morhua) by L-tryptophan supplementation. Aquaculture. 2005; 249(1-4):525-531.

26. Schjolden J, Pulman KG, Pottinger TG, Tottmar O, Winberg S. Serotonergic characteristics of rainbow trout divergent in stress responsiveness. Physiology \& behaviour. 2006; 87(5):938-947.

27. Ahmed I, Khan MA. Dietary tryptophan requirement of fingerling Indian major carp, Cirrhinus mrigala (Hamilton). Aquaculture research. 2005; 36(7):687-695.

28. Fatma AS, Khan MA. Dietary tryptophan requirement of fingerling rohu, Labeo rohita (Hamilton), based on growth and body composition. Journal of the World Aquaculture Society. 2010; 41(5):700-709.

29. Ciji A, Sahu, NP, Pal AK, Akhtar MS. Dietary L-tryptophan modulates growth and immuno-metabolic status of Labeo rohita juveniles exposed to nitrite. Aquaculture research. 2015; 46(8):2013-2024.

30. Zehra S, Khan MA. Dietary tryptophan requirement of fingerling Catla catla (Hamilton) based on growth, protein gain, RNA/DNA ratio, haematological parameters and carcass composition. Aquaculture nutrition. 2015; 21(5):690-701.

31. Akiyama T, Murai T, Mori K. Role of tryptophan metabolites in inhibition of spinal deformity of chum salmon fry caused by tryptophan deficiency. Nippon Suisan Gakkaishi. 1986; 52:1255-1259.

32. Kumar P, Kailasam M, Sethil SN, Sukumaran K, Biswas $\mathrm{G}$, Subburaj $\mathrm{R}$ et al. Effect of dietary L-tryptophan on cannibalism, growth and survival of Asian seabass, Lates calcarifer (Bloch, 1790) fry. Indian Journal of Fisheries. 2017; 64:28-32.

33. Chi CC, Shiu YL, Lin HL, Liu CH. Immune response and disease resistance of barramundi, Lates calcarifer (Bloch), offered diets supplemented with replete levels of tryptophan or whey. Journal of the World Aquaculture Society. 2018; 49(1):127-140.

34. Falcon J, Migaud H, Munoz-Cueto JA, Carrillo M. Current knowledge on the melatonin system in teleost fish. General and comparative endocrinology. 2010; 165(3):469-482.

35. Carrillo-Vico A, Guerrero JM, Lardone PJ, Reiter RJ. A review of the multiple actions of melatonin on the immune system. Endocrine. 2005; 27(2):189-200.

36. Fenwick JC. Demonstration and effect of melatonin in fish. General and Comparative Endocrinology. 1970; 14(1):86-97.

37. De Vlaming VL. Environmental and endocrine control of teleost reproduction. Control and sex in fishes. 1974; 1383.

38. Urasaki H. Effects of restricted photoperiod and melatonin administration on gonadal weight in the Japanese killifish. Journal of Endocrinology. 1972; 55(3):619-620.

39. Iwamatsu T. Studies on oocyte maturation of the medaka, Oryzias latipes. VI. Relationship between the circadian cycle of oocyte maturation and activity of the pituitary gland. Journal of Experimental Zoology. 1978; 206(3):355-363.

40. Sundararaj BI, Keshavanath P. Effects of melatonin and prolactin treatment on the hypophysial-ovarian system in the catfish, Heteropneustes fossilis (Bloch). General and comparative endocrinology. 1976; 29(1):84-96.

41. Keshavanath P. Effects of estradiol-17beta and melatonin treatment on the hypophysis, testes and seminal vesicles of the catfish, Heteropneustes fossilis (Bloch) in the prespawning season. Mysore journal of agricultural sciences. 1981; 15:136-141.

42. Garg SK. Effect of pinealectomy, eye enucleation, and melatonin treatment on ovarian activity and vitellogenin levels in the catfish exposed to short photoperiod or long photoperiod. Journal of pineal research. 1989; 7(2):91104.

43. Borg B, Ekström P. Gonadal effects of melatonin in the three-spined stickleback, Gasterosteus aculeatus L., during different seasons and photoperiods. Reproduction Nutrition Développement. 1981; 21(6A):919-927.

44. Borg B. Androgens in teleost fishes. Comparative Biochemistry and Physiology Part C: Pharmacology, Toxicology and Endocrinology. 1994; 109(3):219-245.

45. Aripin SA, Jintasataporn O, Yoonpundh R. Effects of Melatonin on Clarias Macrocephalus Female Broodstock Performance. International Journal of Sciences: Basic and Applied Research. 2015; 21(1):129-137.

46. Huber R, Smith K, Delago A, Isaksson K, Kravitz EA. Serotonin and aggressive motivation in crustaceans: altering the decision to retreat. Proceedings of the National Academy of Sciences. 1997; 94(11):5939-5942.

47. Huber R, Delago A. Serotonin alters decisions to withdraw in fighting crayfish, Astacus astacus: the motivational concept revisited. Journal of Comparative Physiology A. 1998; 182(5):573-583. 